\title{
CAMILO E PROUST: APROXIMAÇÕES
}

\author{
Moizeis Sobreira de Sousa ${ }^{1}$
}

RESUMO: Este artigo tem por objetivo mostrar as possíveis similaridades que tocam a obra de Camilo Castelo Branco e Marcel Proust, particularmente no que concerne à concepção de romance e/ou literatura.

PALAVRAS-CHAVE: Camilo Castelo Branco; Marcel Proust; romance; Amor de Perdição.

RÉSUMÉ: Le but de cet article est de montrer les ressemblances entre les œuvres de Camilo Castelo Branco et de Marcel Proust, en particulier les rapports entre leurs conceptions de roman et/ou de littérature.

MOTS-CLÉS: Camilo Castelo Branco; Marcel Proust; roman.

\footnotetext{
${ }^{1}$ Mestrando do Programa de Pós-Graduação em Literatura Portuguesa da Universidade de São Paulo. Esta produção tem o apoio da FAPESP.
} 
A leitura da produção ficcional de Camilo Castelo Branco tem sido norteada, em grande parte, por dois parâmetros: a sua relação com o romantismo (esse autor é tido como o expoente máximo do ultra-romantismo português) e a relação que os críticos estabeleceram entre sua vida e obra - freqüentemente, uma é compreendida através da outra. Com muita facilidade, encontramos ensaios e artigos em que a ênfase recai sobre a procura de semelhanças entre eventos narrados na ficção e acontecimentos biográficos ${ }^{2}$. À guisa de exemplo, tomemos as palavras de Feliciano Ramos:

Camilo formou o espírito dentro do clima espiritual do romantismo. A doentia sentimentalidade dos românticos, com a emocionante megalomania da dor, o gosto da melancolia e do cepticismo, transmitiu-se a Camilo, através de leituras, jornais, livros e revistas, e por intermédio do convívio social (...). Entre os seus antepassados, não é difícil descobrir gente falha de integridade psíquica e moral, em que se acusa a demência, o estouvamento e a criminalidade. O momento romântico e ancestralidade mórbida ajudam a explicar tragédias, as perversões, os crimes, os escândalos e imoralidades que povoam seus romances. (RAMOS, 1950, p. 496-497)

Se os pressupostos românticos e a biografia do autor em questão fossem os aspectos fundamentais da sua obra, certamente o interesse pela mesma teria desaparecido quando a estética romântica deixou de ser preponderante. No entanto, sua obra continua encontrando recepção mais de um século depois da morte do autor, provavelmente por possuir elementos que ultrapassem os movimentos literários e estendam-se para além da vida particular de Camilo. É importante destacar que não se pretende negar a relevância do contexto sócio-cultural e da tradição artístico-literária na compreensão da obra.

\footnotetext{
${ }^{2}$ Cabe ressaltar que a crítica biográfica não é adotada unanimemente pelos estudiosos que se dedicam à ficção camiliana. Críticos como Abel Barros Baptista e Paulo Franchetti, por exemplo, oferecem, em suas análises, alternativas a essa corrente crítica. O primeiro trouxe à luz os textos $O$ Inexorável Romancista e Camilo e a Revolução Camiliana, nos quais a obra de Camilo adquire valor pela contribuição que deu à implantação do romance em Portugal. Seguindo essa linha interpretativa, Franchetti escreveu A Novela Camiliana, texto que dialoga criticamente com a crítica biografista e propõe novas chaves de leitura para o legado ficcional camiliano, tais como a construção textual, o estilo, a estrutura narrativa, dentre outras. Seria possível ainda fazer referência a outros críticos e textos que não adotam o viés biografista, todavia, dados os objetivos deste trabalho - fazer o levantamento do modo como os críticos biográficos lêem a ficção camiliana - essa questão não será aqui aprofundada.
} 
Reconhecemos a devida importância do mundo referencial em que a criação ficcional camiliana se inspirou, todavia consideramos incompleta uma leitura que priorize apenas uma reflexão sobre as implicações estético-doutrinárias subjacentes ao período no qual o autor exerceu sua atividade literária.

Alexandre Cabral é outro defensor da interpretação que vincula a obra à vida de Camilo. Esse crítico afirma que há muitas semelhanças entre ocorrências reais e narradas na ficção:

De tal maneira o comportamento dos heróis se assemelha, se entrelaça, se ajusta à desconcertante personalidade do seu criador, multiforme e contraditória; tão coincidentes são as dramáticas situações da vida real, que lhe são impostas ou por ele imaginadas (...), com os conflitos da ficção, que no nosso espírito perdura longamente esta estranha hipótese: as personagens vivem na novela os diabólicos passos da existência (...), quantas vezes numa antevisão profética e satânica, ou é o romancista que se compraz em reviver fisicamente os dramas da sua criação? (CABRAL, 1961, p. 09)

É possível que essa aparente similaridade seja resultado de uma produção de sentido e de uma implicação estética. Camilo, que era um escritor que vivia da sua produção literária, esforçou-se por construir uma legenda que conquistasse público para sua própria obra, de modo a oferecer aos seus leitores o que eles procuravam nos livros amores passionais, vida do autor como objeto de ficção, por exemplo. O que causa surpresa é o fato de essa conjunção continuar agindo sobre a recepção da obra mais de cem anos depois da morte de Camilo. Vários estudiosos continuam norteando a análise da ficção camiliana pelo artifício crítico que o próprio ficcionista ajudou a instaurar. Entre esses estudiosos, incluem-se José Saraiva e Oscar Lopes, autores da canônica História da Literatura Portuguesa (1996).

Se atentarmos para as posições críticas de Camilo a respeito de sua obra, nos daremos conta de que ele indica outras chaves de leitura. No prefácio escrito para a segunda edição de Amor de Perdição, o romancista afirma: 
Este livro (...) teve recepção de primazia sobre todos os seus irmãos (...). Não aprovo a qualificação (...). É grande parte favorável, embora insustentável juízo, a rapidez das peripécias, a derivação concisa do diálogo para os pontos essências do enredo, a ausência de divagações filosóficas, a lanheza da linguagem e desartifício das locuções. Isto quanto a mim, não pode ser um merecimento absoluto. $\mathrm{O}$ romance que não estribar em outras recomendações mais sólidas deve ter uma voga pouco duradoura. Estou convencido de que o romance, (...) tem de firmar sua duração em alguma espécie de utilidade, tal como o estudo da alma, ou a pureza do dizer. E dou mais pelo segundo merecimento; que a alma está sobejamente estudada e desvelada nas literaturas antigas, em nome e por amor das quais muita gente abomina o romance moderno. (CASTELO BRANCO, 1997, p. 13-14)

A partir da leitura desse fragmento, podemos perceber que o autor contesta as qualidades destacadas pelos críticos nesse livro, reputando-as por "insustentável juízo". Para ele, esses elementos (rapidez das peripécias, a derivação concisa do diálogo para os pontos essências do enredo) não podem, sozinhos, sustentar um romance, sob pena de reduzi-lo ao mero desenvolvimento de uma intriga romântica, conforme aponta no prefácio que a escreveu para a quinta edição da obra supracitada. Em contrapartida, Camilo dá ênfase para os procedimentos construtivos; para o exercício do escritor com a linguagem; para "a pureza do dizer". Tal ponto de vista o aproxima da concepção de romance e de literatura que vai predominar a partir dos últimos decênios do século XIX, estendendo até a pós-modernidade. Essa concepção funda-se essencialmente no processo de construção textual.

Comparando as posições críticas do romancista português com as do escritor francês Marcel Proust no que diz respeito à visão sobre a escrita, pode-se encontrar similaridades de ponto de vista. De acordo com Aguinaldo José Gonçalves, a linha mestra de Proust esteve sempre voltada para um alvo: perscrutar o inteiriço das obras e reconhecerlhes o que considerava estilo ${ }^{3}$, verificando a intricada conexão entre a obra de arte e a realidade que lhe serviu de matéria-prima. Gonçalves nota que isso derivava de um

${ }^{3}$ Para Proust, o estilo é a qualidade original de uma obra de arte. Sendo assim, não se trata de uma forma de embelezamento ou uma questão de técnica, mas uma qualidade da visão, uma revelação do universo particular que cada um de nós vê e que os outros vêem. 
exercício de linguagem, cujo objetivo era rastrear paulatinamente a realidade, por meio das coisas e dos seres, feitos linguagem, e por ela resgatados em forma de imagem. "Esse modo de lidar com as coisas do espírito lhe permitiu penetrar fundo no procedimento mimético de representação, realizando a verdadeira bricolagem com o mundo vivido, por meio do mergulho na linguagem." (GONÇALVES, 1994, p. 18). Nesse sentido, não se pode afirmar, como querem os críticos camilianos, que a realidade condiciona a arte. Na verdade, esta submete aquela, através da linguagem, a um processo de desconstrução e reconstrução simultânea, gerando um produto novo, afastando-se do biografismo e da representação rasteira do real. Trata-se de um esforço de captura dos "retalhos do real" - condição primária para a realização de um trabalho literário.

A forma como a realidade é tratada nesse trabalho pode ser comparado a uma metamorfose. Primeiro ocorre a captura, depois a destruição e, finalmente, a remontagem. Em Proust, a noção de realidade está ligada à relação entre sensações e lembranças. Sendo assim, a idéia objetiva passível de ser feita do real é descartada. Confere-se mais importância ao exercício de linguagem, que grosseiramente denominaremos produto final, do que à matéria-bruta, isto é, à realidade.

Parece ser fundamental para os autores em questão o processo de criação, e não exatamente a criatura em si. Por não atentar para isso, a crítica camiliana confunde a obra de arte com a argila de que se valeu o romancista, e com o mundo referencial que o circundava. Deslocou-se o ponto de vista crítico da arte para a história. Deve-se ter em mente que "as circunstâncias em que vivia o artista, os fluxos culturais que o envolvem (...) de nada valem ao destino da arte, não a explicam.” (GONÇALVES, 1994, p. 24).

Parte da crítica camiliana e parte da crítica proustiana, arrisco dizer, têm se esforçado em buscar nas obras desses autores, a trajetória biográfica dos mesmos. Entretanto, parece que, para eles, a crítica deveria empreender esforços para descobrir os "elementos formais da alma de um escritor" e não a vida destes em suas obras.

Por entender que o motor da obra literária é o processo de construção, Marcel Proust formulou parte do seu ponto de vista crítico opondo-se ao mais importante crítico 
francês do século XIX - Sainte-Beuve. Esse crítico propôs um método que partia das circunstâncias de vida de um autor para se chegar a uma avaliação de sua obra. É possível que a centralização dos trabalhos críticos no escritor estivesse relacionada ao valor que o romantismo dava ao indivíduo e ao gênio. Com efeito, os estudos literários enfatizavam a biografia, em detrimento da análise textual. Interessava aos críticos reconstituir o autor na obra. Para isso, era essencial um estudo da vida quotidiana dos seus ancestrais ${ }^{4}$, da sua história, e tal estudo deveria oferecer respostas a determinadas questões: qual o primeiro grupo a quem o autor se associou; o primeiro livro que o tornou famoso; o momento de seu declínio, o fato decisivo da sua decadência; o que pensava ele da religião. Como foi afetado pela natureza? Como se comportava com relação às mulheres? Era rico ou pobre? Como era seu modo de vida? Qual era seu vício ou sua fraqueza? Tais questões eram freqüentemente respondidas com detalhes, anedotas ou mesmo bisbilhotices sobre sua vida quotidiana do autor.

Além de tentar encontrar o autor na obra, Sainte-Beuve procurou encontrá-lo nos movimentos literários. Esse tipo de crítica remete para a forma como alguns críticos portugueses lidam com a ficção camiliana. Como vimos anteriormente, os estudiosos dessa obra conceberam uma interpretação que a vincula à biografia de seu autor e à estética romântica.

Para Proust, o método de Sainte-Beuve desprezava o fato de que um livro é produto de um outro eu e não daquele que se manifesta nos costumes, na sociedade. Em razão disso, pode-se dizer que o eu social não é o responsável por uma obra.

Em nenhum momento Sainte-Beuve parece ter compreendido que há particularidades na inspiração e no trabalho literário, e que estas o diferenciam por completo das ocupações dos outros homens e das ocupações do escritor. Não fazia distinção entre a ocupação literária onde, na solidão, fazemos calar as palavras que existem para os outros tanto quanto para nós, e com as quais, mesmo solitárias, julgamos as

\footnotetext{
${ }^{4} \mathrm{O}$ estudo da vida do autor e dos seus ancestrais propostos por Sainte-Beuve lembra o método utilizado por Feliciano Ramos para explicar o caráter de Camilo Castelo Branco. Segundo ele, como vimos anteriormente, o momento romântico e ancestralidade mórbida ajudam a explicar tragédias, as perversões, os crimes, os escândalos e imoralidades que povoam seus romances.
} 
coisas sem que sejamos nós mesmos, nós nos recolocamos face a face com nós mesmos, esforçamo-nos por entender, e por restituir, o verdadeiro som de nosso coração - e a conversação (...), que não é senão aparência enganosa da imagem que dá aqui algo de mais exterior e mais vago (à profissão), algo de mais aprofundado e recolhido à intimidade. (...). Dirá sempre que a vida do homem de letras limita-se ao gabinete (...), mas continuará não compreendendo este mundo único, fechado, sem comunicação com o exterior, que é a alma do poeta (...) E por não ter visto o abismo que separa o escritor do homem de mundo, por não ter entendido que o eu do escritor só se mostra em seus livros, e que ele não mostra aos homens do mundo. (PROUST, 1998, p. 55-56).

Como ressalta da leitura desse trecho, na concepção de Proust, a essência da obra não está nas relações do escritor com o mundo que o cerca ou com os movimentos literários. Fica evidente sua opção por um eu profundo. Seria este o genitor da criação literária. Assim, os procedimentos críticos cuja ênfase recai sobre o eu social só podem ter validade para a história do escritor e dos movimentos literários. A obra, desse modo, fica subordinada a questões biográficas e temporais. Pouco ou quase nada se recorre às implicações artísticas que estão na base do texto literário.

No século XIX a noção de indivíduo estava ligada à importância do conceito de gênio, oriunda do romantismo alemão. Isso talvez justifique as posições simplistas do crítico francês naquele momento. No entanto, como explicar que um número considerável de críticos lusitanos dos séculos XX e XXI continue adotando práticas críticas que se assemelham ao método de Sainte-Beuve, para estudar a obra de Camilo e de outros tantos escritores? Não seria o momento da crítica deslocar o foco das questões históricas e biográficas paras as artísticas? Abandonaríamos, então, o gesso das classificações tipológicas. O romantismo e os elementos biográficos, apontados na ficção camiliana, deixariam de ocupar papel de destaque e passariam a ser apenas uma fração da matéria bruta a partir da qual o romancista desencadearia o processo de metamorfose inventiva. $\mathrm{O}$ eu social seria apenas um coadjuvante no cenário crítico. 
Aguinaldo Gonçalves afirma que a busca do eu profundo em Proust equivale ao exercício do narrador ao pôr em prática as suas iluminações da memória involuntária ${ }^{5}$ para recriar as experiências da vida num trabalho de arte. Essa busca pode ser comparada à confecção de um retrato sem moldura, que teria como modelo primeiramente a experiência, a qual se transformaria em escritura e teria como imagem um outro retrato: "Antes que esse retrato pudesse ser fixado, a imagem se estilhaçou (...) e retratou-se em signos que se movimentam em infinitas direções. Tornou-se um campo blindado propenso a metamorfoses; tornou-se a poção dialética entre arte e vida" (PROUST, 1988, p.11).

É mais adequado à arte que a crítica tome por objeto esse retrato sem moldura. Assim compreenderíamos, como propôs Proust, quais as afinidades secretas, as metamorfoses necessárias, existentes entre a vida de um escritor e sua obra, entre a realidade e a arte, ou antes, entre as aparências de vida. Contudo, como nota Gonçalves, muitas vezes o crítico tem sede de apresentar um conhecimento, uma cultura, e por isso não consegue silenciar quando deve. Tal avidez o impede de se dar conta de que a obra de arte varia, oscila, inviabilizando, assim, a recorrência a cânones comuns para todas as formas de criação. Nesse sentido, a maneira mais apropriada para se entender as obras de Castelo Branco e Proust é recorrer a uma chave que não seja a da porta dos movimentos literários e/ ou a do eu social. Deve-se ter em mente que o caminho que leva a compreensão das mesmas não é linear; ele passa por um labirinto.

A realização do projeto proustiano requer múltiplos níveis e dimensões de montagem textual, em planos diferentes que se articulam, se sobrepõem e se entrecruzam, "tudo convergindo numa espécie de revelação. São associações simultâneas, blocos sinestésicos, que dão forma às nebulosas do espírito. Surgem no discurso as belas e

\footnotetext{
${ }^{5}$ A obra de Proust, como sabemos, problematiza a relação dialética entre linguagem e realidade. Para isso, recorreu à relação que se estabelece entre os significados e significantes dos signos, recuperando aquilo que era apenas nebuloso no seu pensamento. "Esse exercício de mimesis da própria linguagem tem como resultado a tensão do limite extremo em que se opera a transubstancialização da realidade referencializada, para a realidade referencializável da obra" (PROUST, 1988, p. 14). Esse processo é denominado por Proust como memória involuntária. Nesse sentido, a inteligência não ocuparia um lugar de primazia. Ela seria responsável apenas pela ordenação dos processos associativos advindo das sensações, ou seja, da memória involuntária.
} 
complexas superposições de planos" (Proust, 1988, p.20). Nesse ponto, pode-se estabelecer mais um paralelo entre o romancista português e o francês. Aquele parece ter construído narrativas de focalizações múltiplas, engendrando uma estrutura narrativa em dois ou mais níveis textuais, o que certamente demandou diversas dimensões de montagem. Vale ressaltar que a noção de memória involuntária parece não estar presente na fícção do primeiro. Talvez esteja aqui uma diferença entre o seu estilo e o de Proust.

A articulação interna da linguagem, os arranjos das categorias de cada meio expressivo, na busca da ampliação dos seus limites - traço condutor da modernidade -, geram uma força diferente, uma convulsão das formas que exigem do receptor uma postura mental diferente. São obras estruturalmente dinâmicas, e tematicamente estáticas que, como resultado, geram novas relações distintas e muito mais intensas, é claro, que os modelos tradicionais. (GONÇALVES, 1994, p. 28).

Embora essa afirmação faça referência a Proust e a outros artistas da modernidade, ela pode, em certa medida, ser aplicada também à ficção camiliana. A "convulsão das formas" não encontrou na crítica portuguesa uma postura mental adequada aos procedimentos narrativos de Camilo. Provavelmente por causa disso, sua obra foi lida romântico e biograficamente. O romancista destaca no prefácio a segunda edição de Amor de Perdição a importância da "pureza do dizer" no momento da construção do romance. Não seria forçoso afirmar que a pureza do dizer poder ser equiparada à "articulação interna da linguagem, na busca da ampliação dos seus limites" - traço condutor da modernidade, como nos lembra a citação anterior.

Como vimos, Sainte-Beuve (...) concebe a literatura assim como todas as séries das Lundis, que poderão ser relidas talvez, mas que foram escritas em sua hora, importando-se com a opinião dos bons juízos, para agradar, e sem muito contar com a posteridade. Via a literatura como uma categoria de tempo (...) parecia-lhe uma coisa da época. (PROUST, 1988, p. 58).

Esse comentário que Proust faz a respeito da forma como Sainte-Beuve nos dá, de certa forma, a visão que críticos como Saraiva, Lopes, Ramos e Cabral têm da obra de 
Camilo. No início destacamos que ela continua encontrando recepção mais de um século após a morte de seu autor. Uma provável explicação para isso seria a existência de elementos mais sólidos que a biografia e o contexto histórico.

É bem verdade que Camilo importava-se em agradar a opinião dos bons juízos, isto é, dos editores e dos leitores dos seus livros, já que vivia do ofício literário. No entanto, estribou, voluntária ou involuntariamente, seus romances em recomendações que visavam a uma voga duradoura. Se por um lado, abria espaço para o eu social na sua novelística, por outro soube imprimir as marcas do eu profundo. O primeiro era uma legenda para alcançar a recepção oitocentista. O segundo, o elemento que fez sua produção chegar ao século XXI e muito provavelmente fará chegar aos séculos posteriores. Soube articular por meio da linguagem a contemporaneidade (traço ínfimo) e a posterioridade. O que é problemático é o fato da crítica se deter na primeira. O próprio autor demonstrava ter consciência de que os subsídios oferecidos ao seu tempo teriam curta duração.

Provavelmente Camilo não contava com a vida após a morte da legenda que criou. Tem-se a impressão de que esperava uma postura crítica diferente daquele que expomos ao longo desse texto. Partir do retrato estilhaçado e sem moldura, perdido nos campos da linguagem parece ser mais adequado, já que um livro é produto de um eu diferente daquele que manifestamos nos nossos hábitos sociais.

\section{Referências Bibliográficas}

CABRAL, Alexandre. Subsídio para uma Interpretação da Novelística Camiliana. Lisboa: Livros Horizonte, 1985.

CASTELO BRANCO, Camilo. Amor de Perdição. São Paulo: Ática: 1997.

GONÇALVES, Aguinaldo José. Prefácio. In: PROUST, Marcel. Nas trilhas da crítica. São Paulo: Imaginário/Edusp, 1994. 
GONÇALVES, Aguinaldo José. Prefácio. In: PROUST, Marcel. Contre sainte-beuve: notas sobre crítica e literatura. São Paulo: Iluminuras, 1988.

PROUST, Marcel. Contre sainte-beuve: notas sobre crítica e literatura. Trad. Haroldo Ramazini. São Paulo: Iluminuras, 1988.

RAMOS, Feliciano. História da Literatura Portuguesa. Braga: Cruz, 1950. 